\title{
Identification and characterization of critical cis-acting sequences within the yeast Ty1 retrotransposon
}

\author{
ERIC C. BOLTON, CANDICE COOMBES, YOLANDA EBY, MATTIAS CARDELL, and JEF D. BOEKE \\ Department of Molecular Biology and Genetics, The Johns Hopkins University School of Medicine, Baltimore, Maryland 21205, USA
}

\begin{abstract}
The yeast long terminal repeat (LTR) retrotransposon Ty1, like retroviruses, encodes a terminally redundant RNA, which is packaged into virus-like particles (VLPs) and is converted to a DNA copy by the process of reverse transcription. Mutations predicted to interfere with the priming events during reverse transcription and hence inhibit replication are known to dramatically decrease transposition of Ty1. However, additional cis-acting sequences responsible for Ty1 replication and RNA dimerization and packaging have remained elusive. Here we describe a modular mini-Ty1 element encoding the minimal sequence that can be retrotransposed by the Ty1 proteins, supplied in trans by a helper construct. Using a mutagenic screening strategy, we recovered transposition-deficient modular mini-Ty1-HIS3 elements with mutations in sequences required in cis for Ty1 replication and integration. Two distinct clusters of mutations mapped near the $5^{\prime}$-end of the Ty1 RNA. The clusters define a GAGGAGA sequence at the extreme 5 '-end of the Ty1 transcript and a complementary downstream UCUCCUC sequence, $264 \mathrm{nt}$ into the RNA. Disruption of the reverse complementarity of these two sequences decreased transposition and restoration of complementarity rescued transposition to wild-type levels. Ty1 cDNA was reduced in cells expressing RNAs with mutations in either of these short sequences, despite nearly normal levels of Ty1 RNA and VLPs. Our results suggest that the intramolecular interaction between the $5^{\prime}$-GAGGAGA and UCUCCUC sequences stabilizes an RNA structure required for efficient initiation of reverse transcription.
\end{abstract}

Keywords: RNA; intramolecular interaction; mutagenesis

Ty1 is one of five types of long terminal repeat (LTR) retrotransposons inhabiting the genome of the yeast Saccharomyces cerevisiae. LTR retrotransposons, such as Ty1, are similar to retroviruses in many aspects (Boeke and Stoye 1997; Voytas and Boeke 2002). Analogous to retroviruses, Ty1 elements consist of a central coding region flanked by directly repeated LTRs, which are divided into the U3, R, and U5 regions. The Ty1 lifecycle, a streamlined version of the retroviral lifecycle, can be divided into three phases: (1) expression and assembly, (2) reverse transcription, and (3) integration. Transcription of Tyl produces a terminally redundant RNA molecule, which serves dual functions. First, translation of the element-encoded RNA generates the structural protein Gag and enzyme Pol, which are required for transposition, specifically for replication and integration of Ty1. Pol is made as a Gag-Pol read-through protein by

Reprint requests to: Jef D. Boeke, Department of Molecular Biology \& Genetics, Johns Hopkins University School of Medicine, 339 Broadway Research Building, 733 North Broadway, Baltimore, MD 21205, USA; email jboeke@jhmi.edu; fax (410) 502-1872.

Article published online ahead of print. Article and publication date are at http://www.rnajournal.org/cgi/doi/10.1261/rna.7860605. translational frameshifting (Belcourt and Farabaugh 1990). Gag and Gag-Pol proteins are coassembled with Ty1 RNA and the yeast initiator $\operatorname{tRNA}_{i}{ }^{\text {Met }}$ within the cytoplasm, forming virus-like particles (VLPs) (Chapman et al. 1992; Roth 2000; Voytas and Boeke 2002). VLPs are direct transposition intermediates in which reverse transcription occurs (Garfinkel et al. 1985; Eichinger and Boeke 1988). Second, during Tyl replication, as in retroviruses, the terminally redundant RNA, the genetic material for transposition (Boeke et al. 1985), is converted to a double-stranded DNA copy by Ty1 reverse transcriptase (Garfinkel et al. 1985).

In retroviruses, several cis elements have been identified and characterized. These RNA sequences mediate many processes, several of which include retroviral RNA dimerization, packaging, and reverse transcription (Telesnitsky and Goff 1993; Paillart et al. 1996b, 2004; Rabson and Graves 1997; Swanstrom and Wills 1997). The common theme among these cis-acting sequences is their location near the termini of the retroviral RNA transcript. In agreement with this, the sequences required in cis for retrotransposition of the yeast Tyl element were previously mapped in or near the LTRs (Xu and Boeke 1990). Several cis elements required for Ty1 replication have been described in 
detail including the primer binding site (PBS), box 0 , box 1 , and box 2.1 as well as the poly-purine tract 1 (PPT1) (Boeke et al. 1988a; Chapman et al. 1992; Heyman et al. 1995; Friant et al. 1998). Additionally, the genomic RNA in Ty1 VLPs reportedly exists as a noncovalent dimer (Feng et al. 2000). However, little is known about the sequences needed for RNA dimerization or packaging other than preliminary results from deletion experiments suggesting a critical sequence 230-580 nt into the Ty1 transcript, within the PvuIIHpaI fragment (Xu and Boeke 1990).

We report the use of the modular mini-Tyl system designed to identify and study the cis-acting sequences within the Tyl element required for transposition. The modular mini-Tyl element consists of a Ty1 element, Ty1-H3, in which the C-terminal half of GAG and the entire POL ORF have been deleted and replaced with the yeast selectable marker, HIS3. The Tyl-encoded proteins, provided in trans by a helper plasmid, affect the transposition of the miniTy1-HIS3 RNA. While the helper construct encodes the Gag and Pol proteins, it is incapable of retrotransposition because the 3'-LTR was deleted (Xu and Boeke 1990). The studies described here detail a new helper plasmid further crippled by mutation of the PBS.

Localized mutagenesis of the Tyl sequences contained within the minimal mini-Ty1-HIS3 element by polymerase chain reaction (PCR) was performed and revealed several clusters of previously known and unknown sequences required for transposition. Interestingly, disrupting a possible base-pairing interaction between two sequences near the 5 '-end of the Tyl RNA dramatically inhibited transposition. The transposition defect in these mutants lies between VLP assembly and the completion of reverse transcription. Our results suggest that the intramolecular interaction between the GAGGAGA sequence within the repeat $(\mathrm{R})$ region at the $5^{\prime}$-end of the Tyl transcript and the downstream UCUC CUC sequence, $264 \mathrm{nt}$ into the pGTy1-H3 transcript may stabilize an RNA structure required for efficient initiation of reverse transcription.

\section{RESULTS}

\section{A modular mini-Ty1-HIS3 system for studying cis elements}

To identify cis-acting sequences within the Tyl RNA involved in the mechanism of retrotransposition, a mutagenic screen based on the transposition of a mini-Tyl element (Xu and Boeke 1990) was developed. A previous deletion strategy localized the sequences required in cis for Ty1 retrotransposition near the LTRs (Xu and Boeke 1990), thus generating a series of mini-Tyl elements. The minimal mini-Tyl element chosen for this study (Fig. 1A) encodes the first $580 \mathrm{nt}$ and the last $357 \mathrm{nt}$ of pGTyl-H3 RNA (Xu and Boeke 1990). Because mini-Tyls do not encode Tyl proteins, a helper plasmid, which has complete $G A G$ and POL ORFs, a multiply mutated PBS (Chapman et al. 1992) and no $3^{\prime}$-LTR or plus-strand priming region was used to supply Tyl proteins in trans. We show that the mini-Ty1HIS3 RNA encoded by the modular mini-Ty1-HIS3 donor plasmid (URA3 backbone) is transposed, but only in the presence of the helper plasmid (LEU2 backbone) (Fig. $1 \mathrm{~A}, \mathrm{~B})$. The moderate level of background growth present on the selective plate for the wild-type (RAD52) strain containing the transposition-deficient modular mini-Tyl-HIS3 donor plasmid apparently resulted from homologous recombination events between the plasmid and the chromosomal
A

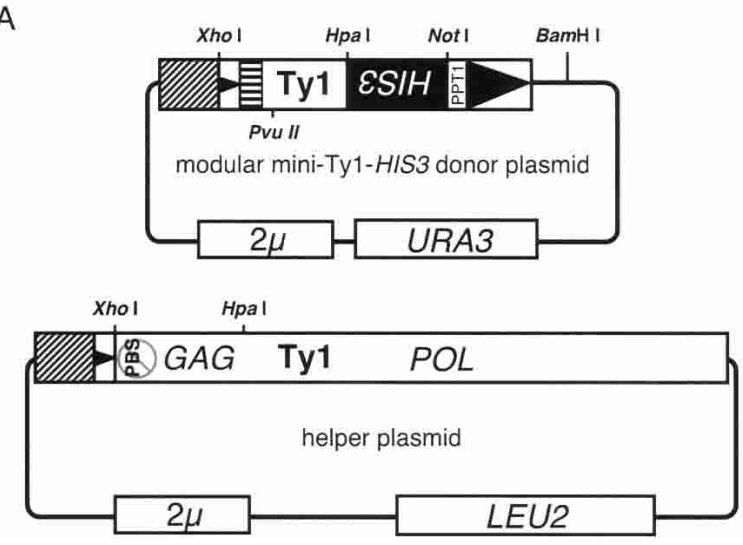

B

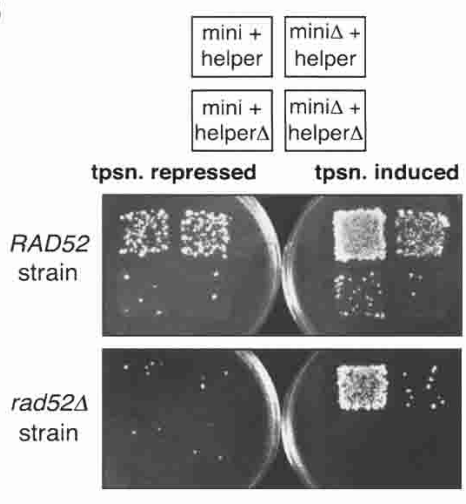

FIGURE 1. The modular mini-Tyl transposition system. (A) Structures of the modular mini-Ty1-HIS3 donor and helper plasmids. The U3 portion of the $5^{\prime}$-LTR (the Ty1 promoter) has been replaced with the inducible GAL1 promoter (striped box). The $2 \mu$ sequence contains a yeast replication origin. pBR322 sequences are indicated by lines, while boxes indicate yeast sequences. The HIS3 marker gene has the opposite transcriptional orientation as the mini-Tyl element. Notice that the helper plasmid lacks a functional PBS as well as the PPT and $3^{\prime}$-LTR, thus it cannot be reverse-transcribed or transposed. GAG and POL refer to the two ORFs of the Tyl element. (B) Transposition of various combinations

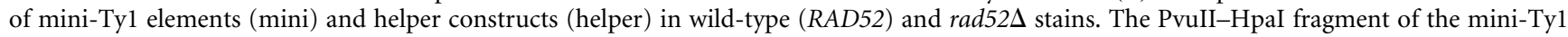
element is deleted in the mini $\Delta$ construct, pECB5K1, and the helper $\Delta$ construct, p425 GAL1 (Mumberg et al. 1995), entirely lacks Ty1 coding sequence. 
Tyls because such growth is absent from the rad52 $\Delta$ strain (Fig. 1B). However, since our mutagenesis strategy requires the endogenous homologous recombination machinery, which includes the Rad52 gene product (Muhlrad et al. 1992), and since the background of recombinants did not interfere with isolation of mutants, we used a RAD52 strain.

\section{Isolation of mutant mini-Ty1s}

To identify critical cis elements required for Ty1 transposition, we screened the transposition phenotype of thousands of mutant modular mini-Ty1-HIS3 elements. This screen qualitatively assays the frequency of mini-Ty1-HIS3 transposition in yeast cells containing mutant modular miniTy1-HIS3 donor plasmids and a helper plasmid. The modular mini-Ty1-HIS3 donor plasmid was mutagenized by a PCR-based method in which mutagenized PCR products were incorporated into either the $5^{\prime}$-region (XhoI-HpaI) or the 3 '-region (NotI-BamHI) of the mini-Ty1-HIS3 element by in vivo gapped-plasmid repair (Muhlrad et al. 1992; Brachmann et al. 1998). The presence of PCR product during transformation resulted in $>160$-fold more transformants than gapped-plasmid alone, while transformation of PCR product alone yielded no transformants. This result suggests that $>99 \%$ of colonies screened were generated by recombination between the PCR product and the gapped plasmid. Colonies containing mutagenized modular miniTy1-HIS3 donor plasmids were screened for transposition defects. The transposition assay consists of a series of replica-plating steps, in which pGal-Tyl expression and transposition are induced on galactose-containing medium, and then scored by qualitative determination of the fraction of $\mathrm{His}^{+}$plasmid-free colonies (see Materials and Methods). All transposition-deficient colonies were patched and retested for transposition and proper donor plasmid segregation (i.e., the ability of cells to lose the modular mini-Ty1-HIS3 donor plasmid). Modular mini-Ty1-HIS3 donor plasmids were rescued from colonies that remained transpositiondeficient and were able to lose the donor plasmid by mitotic segregation. The mutations in recovered mini-Ty1-HIS3 elements were subsequently identified by sequencing.

\section{5'-region mutants}

Approximately 20,000 colonies were assayed for transposition during screening of the $5^{\prime}$-region. Of the 663 primary screen mutants, 98 transposed as wild type does upon retesting, and 242 had acquired the multiply mutated PBS from the helper plasmid; these plasmids likely arose from a triple recombination event between the sequence just $5^{\prime}$ of the XhoI site of the gapped and helper plasmids, the region just 3' of the PBS of the helper plasmid and the PCR product, and the sequence just $3^{\prime}$ of the HpaI site of the PCR product and the gapped plasmid. This uninteresting class of mutants was screened out by a simple PCR-based test (see Materials and Methods). Of the remaining 289 recovered mutant mini-Ty1-HIS3 donor plasmids, 271 were sequenced. Of these 271 plasmids, three had no XhoI-HpaI fragment (presumably these arose by nonhomologous endjoining of the gapped plasmid), 106 had no mutations in the sequenced region, and 162 had mutations within the mutagenized region. Of the latter, 10 had single-base deletions in the $5^{\prime}$-region. Of the 152 remaining mutant mini-Ty1HIS3 elements, 85 had single-base, 44 had double-base, and 17 had triple-base substitutions in the mutagenized region. The remaining six mutants had four or more mutated bases in the $5^{\prime}$-region. Overall, $\sim 81 \%$ of the substitution mutations were transitions and 19\% were transversions.

Mutations that reduced the frequency of transposition of the mini-Ty1-HIS3 element are localized in distinct clusters within the $5^{\prime}$-region (Fig. 2A). As expected, many mutations mapped to the PBS region containing the PBS, box 0 , box 1, and box 2.1, required for interaction of the Ty1 RNA with the yeast initiator $\mathrm{tRNA}_{\mathrm{i}}{ }^{\mathrm{Met}}$ to prime minus-strand synthesis, thus initiating reverse transcription. Two additional clusters of mutations that decrease transposition of the mini-Ty1-HIS3 element appear within the $5^{\prime}$-region. One is just downstream of the PvuII site, while the other one is near the XhoI site, which corresponds to the start site of the mini-Ty1-HIS3 transcript (Fig. 2A, indicated by ${ }^{\star}$ ). Another hotspot for mutations that abolished transposition of the mini-Ty1-HIS3 element corresponds to the TATAbox of the GAL1 promoter, further validating the mutagenesis method. The Gal4-binding sites, located further upstream of the mutagenized region, were not sequenced.

\section{$3^{\prime}$-region mutants}

Almost 13,000 colonies were assayed for transposition during screening of the $3^{\prime}$-region. Of the 313 primary screen mutants, 93 transposed as wild type does during secondary screening tests, 13 exhibited growth defects, 11 failed to segregate the donor plasmid, and five had acquired the multiply mutated PBS from the helper plasmid (this class of mutants could arise by four recombination events between the two plasmids and the PCR product). Of the remaining 191 recovered mutant mini-Ty1-HIS3 donor plasmids, 172 were sequenced. Of these 172 plasmids, one had no NotIBamHI fragment (again presumably arising by nonhomologous end-joining of the gapped plasmid), five had no mutations in the sequenced region, and 166 had mutations within the mutagenized region. Of the 166 mutants, 37 had single-base deletions in the $3^{\prime}$-region. Of the remaining 129 mutant mini-Ty1-HIS3 elements, 26 had single-base, 30 had double-base, and 30 had triple-base mutations in the mutagenized region. The remaining 43 of 129 mutants had four or more mutated bases in the $3^{\prime}$-region. In all, $78 \%$ of the substitution mutations were transitions and $22 \%$ were transversions. 

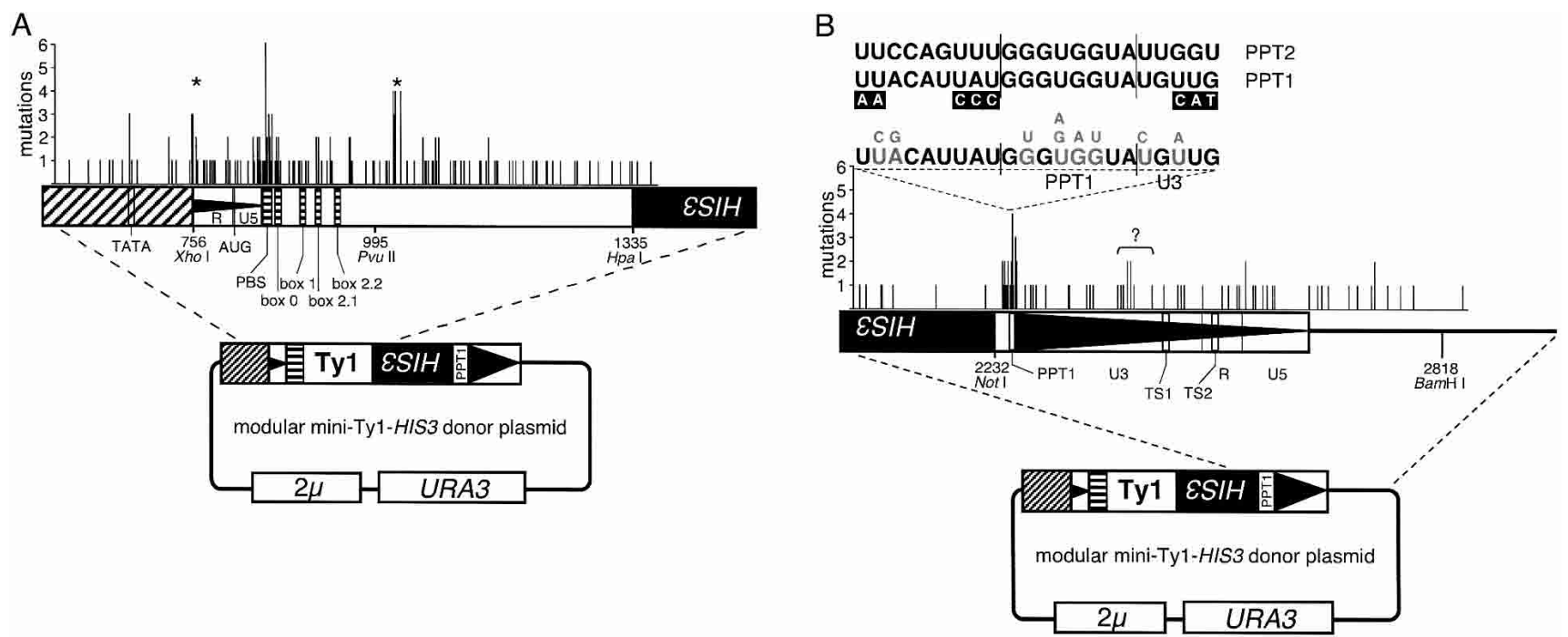

FIGURE 2. Summary of transposition-deficient mini-Ty1-HIS3 elements with one to two mutations. (A) Mutations identified in the $5^{\prime}$-region. Sequences required for priming events during reverse transcription, which include the PBS, box 0, box 1, and box 2.1, are indicated. Vertical black bars indicate the positions of single-nucleotide mutations within the mutagenized region of the mini-Tyl-HIS3 element. The height of the vertical bars indicates the number of times a mutation at that nucleotide position was independently isolated. $\left({ }^{*}\right)$ Two clusters of mutations were in regions not previously known to be required for transposition. (B) Summary of transposition-deficient mini-Tyl-HIS3 elements with one to two mutations in the $3^{\prime}$-region. Sequences required for priming events during reverse transcription, like PPT1, are indicated. For comparison, aligned PPT1, PPT2, and flanking sequences are shown. Previously identified mutations in PPT1 that abolish transposition (Wilhelm et al. 1999) are indicated in small white type on black boxes. Sequence in large gray type indicates single-base mutations on a transposition-deficient mini-Ty1HIS3 element during the original 3 '-region screen. Bases in small gray type denote the mutant nucleotides identified at the position of the mutation.

\section{PPT1 sequence}

Mutations that decreased the transposition frequency of the mini-Ty1-HIS3 element are also localized into distinct clusters within the $3^{\prime}$-region (Fig. 2B). Mutations within the $3^{\prime}$-region that reduced the frequency of the mini-Ty1-HIS3 element transposition clustered in and around the PPT1 sequence, required to prime plus-strand DNA synthesis during reverse transcription (Fig. 2B). The length of this $3^{\prime}$ cluster suggests that the actual sequence required to prime plus-strand synthesis extends further $5^{\prime}$ of the PPT1 sequence itself, as previously proposed by Wilhelm et al. (1999). Based on the results of the $3^{\prime}$-region screen, we propose that as many as eight bases located immediately upstream of PPT1 are required for transposition of the mini-Ty1-HIS3 element. This 8-nt sequence is most likely required for efficient priming during plus-stand strong-stop DNA synthesis.

\section{LTR sequence}

Mutation of the first and third bases of the $3^{\prime}$-U3 sequence reduced transposition of the mini-Ty1-HIS3 element as well. The first U3 nucleotide is crucial for transposition because it determines the sequence of the left end of the DNA element, which is recognized by the IN protein during integration (Braiterman and Boeke 1994; Sharon et al. 1994; Moore et al. 1995). As for the third base of the $3^{\prime}-\mathrm{U} 3$, its relevance to IN substrate specificity remains unclear, but it could be critical for proper IN binding in vivo.

A smaller cluster of mutations mapped within the $3^{\prime}$-U3 sequence just upstream of termination signal 1 (TS1). The significance of this previously unknown region (Fig. 2B, labeled with ?) is still questionable. Unfortunately, no single-mutant mini-Ty1-HIS3 elements were isolated with single-base changes in this cluster. Therefore, the significance of mutations in this portion of the $3^{\prime}$ - $\mathrm{U} 3$ region remains unknown.

\section{Verification of $5^{\prime}$ mutants}

To verify that the mutations within the isolated modular mini-Ty1-HIS3 donor plasmids, indeed, affected transposition and to sort out effects of multiple mutations, fragments containing single-base mutations were subcloned into a "clean" modular mini-Ty1-HIS3 donor plasmid. These single-mutant mini-Tyl-HIS3 donor plasmids were then tested for transposition. Most (49 of 69) of the single-base mutations caused a significant decrease in transposition frequency (Fig. 3A). For "hotspots" with at least three mutations, $88 \%$ (seven of eight sites) of the single-base mutants showed decreased transposition, and for those with two mutations, $86 \%$ (12 of 14 sites) of the single-base mutants were transposition-deficient, suggesting that sites with two mutations are not less "hot" than sites with at least three mutations. Also, the three clusters of mutations within the 

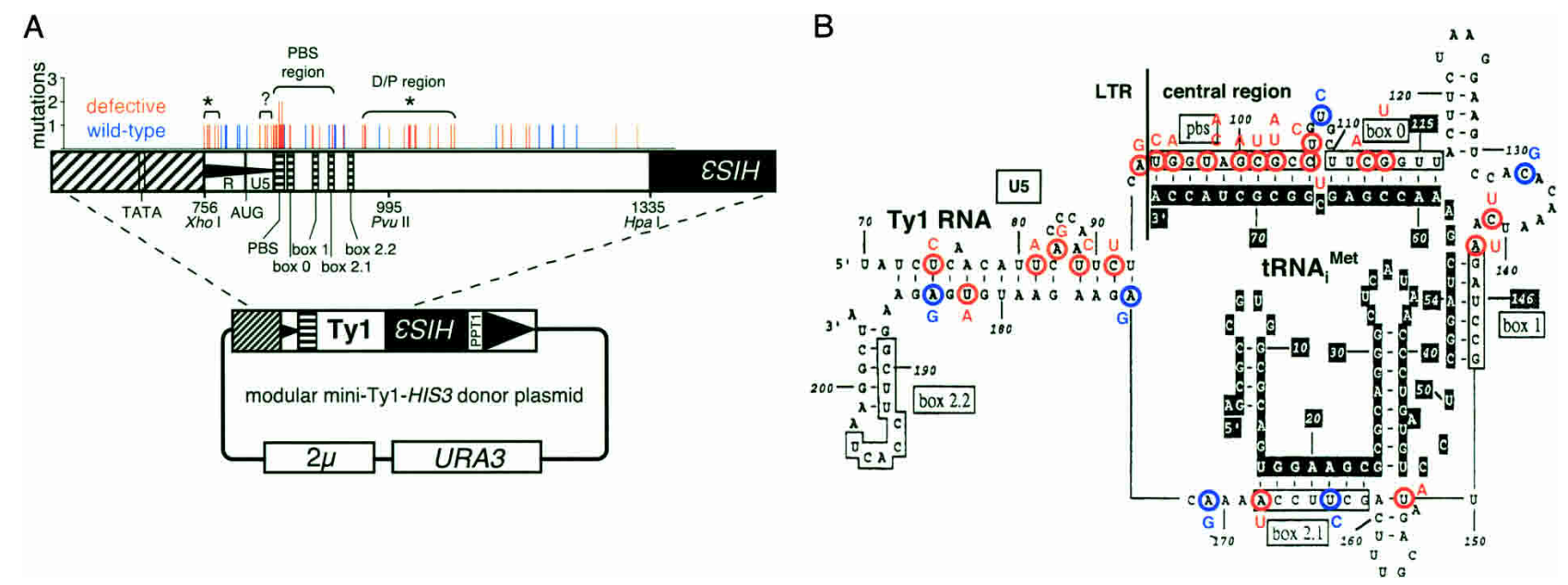

FIGURE 3. Verified mutations that reduce retrotransposition of the mini-Ty1-HIS3 element. (A) Summary of subcloned single nucleotide changes in the $5^{\prime}$-region of the mini-Tyl-HIS3 element and their effect on transposition. Vertical orange bars denote the positions of single-base mutations that reduced transposition, while mutations that did not affect transposition are indicated by blue bars. Bracketed sequences denote $5^{\prime}$-region sequences of interest such as the PBS region, the putative dimerization and packaging (D/P) region, and $5^{\prime}-\mathrm{R}$ and U5 regions, all of which are required for transposition. $\left.{ }^{\star}\right)$ Two clusters of mutations were not known to be required for transposition. $(B)$ The positions of single nucleotide changes in the $5^{\prime}$-U5 and PBS regions and their effect on transposition. Modified from the original predicted secondary structure for the Ty1 RNA (black letters) with the yeast initiator $\mathrm{tRNA}_{\mathrm{i}}^{\text {Met }}$ (white letters on black background) complex (Friant et al. 1996). Orange circles indicate mutated bases that decreased transposition, while mutations that did not affect transposition are circled in blue. The corresponding mutant bases are indicated in orange or blue type.

$5^{\prime}$-region, corresponding to the $5^{\prime}$-end of the RNA, the PBS region, and the putative dimerization and packaging $(\mathrm{D} / \mathrm{P})$ region, were confirmed to be transposition-deficient. In most cases, subcloned single-base mutations that did not decrease transposition were originally isolated as multiply mutated donor plasmids. Many of these had additional mutations within the PBS, box 0 , box 1, and box 2.1 region, and hence their transposition defect resulted from aberrant reverse transcription priming (Boeke et al. 1988a; Chapman et al. 1992; Friant et al. 1998).

\section{5'-U5 and PBS region mutants}

Mutation of several bases toward the end of the $5^{\prime}$-U5 sequence (Fig. 3A, labeled with ?), particularly the last nucleotide, reduced transposition of the mini-Tyl-HIS3 element as well. The last base is crucial for transposition because it determines the sequence of the right end of the DNA element, which is recognized by the IN protein during integration (Braiterman and Boeke 1994; Sharon et al. 1994; Moore et al. 1995). Other required bases within the U5 region (Fig. 3B) may well be responsible for maintaining a proposed Tyl RNA secondary structure (Friant et al. 1996, 1998) as many of the isolated mutants that reduce transposition are predicted to interfere with this structure. The exact role of this interesting portion of the $5^{\prime}-\mathrm{U} 5$ remains to be determined.

Interestingly, no transposition-deficient mini-Tyl-HIS3 elements were recovered with mutations in the translation initiation site (AUG). This suggested to us that the miniTy1-HIS3 element does not need to produce functional Gag protein. To address this hypothesis directly, we assayed the transposition frequency of an AUG to AUU mutant miniTy1-HIS3 element made by site-directed mutagenesis. Surprisingly, the AUG to AUU mutant element transposed poorly, but not as poorly as the negative control, mini $\Delta$. Thus, we are uncertain of the fate of the truncated Gag protein encoded by the mini-Tyls; translatability of Tyl RNA may be a requirement for efficient retrotransposition. The fact that the mini-Ty1-HIS3 element transposes well suggests that the truncated Gag protein does not function in a dominant-negative manner. To further assess our screening strategies, we compared our PBS region findings to those reported previously (Friant et al. 1998). All of the single-base mutations that we isolated within the PBS and box 0 sequences decreased the transposition frequency of the mini-Ty1-HIS3 element (Fig. 3A,B). While no singlebase mutations within box 1 were subcloned and retested, single mutations in the three bases flanking the box 1 sequence decreased transposition. Single-base changes within box 2.1 gave paradoxical results; one mutation did not affect the transposition frequency of the mini-Ty1-HIS3 element (mutation of $\mathrm{U}$ to a $\mathrm{C}$ in GCUUCCA), while another did (mutation of A to U in GCUUCCA). A previous study determined that changing four consecutive nucleotides (mutation of UUCC to AAGU in GCUUCCA) severely affected transposition (Friant et al. 1998).

\section{Two intriguing clusters of mutations in the $5^{\prime}$-region}

All tested single-base mutations near the extreme $5^{\prime}$-end of the mini-Tyl-HIS3 RNA and within the cluster down- 
stream of the PvuII site also significantly inhibited transposition of the mini-Ty1-HIS3 element (Fig. 4, indicated by ${ }^{*}$ ). Considering that we isolated 85 single-base mutants within the $\sim 800$-bp sequenced portion of the mutagenized 5 '-region, we expected to recover 1 mutant per 9 bp by random distribution. Inspection of this downstream sequence revealed that mutations in any of four consecutive nucleotides within the CUCCUC sequence of the Tyl RNA significantly reduced transposition. Of the four mutated nucleotide positions, three were recovered as single-base mutants, significantly greater than predicted by random distribution. We focused our attention on this CUCCUC sequence because its location within the $5^{\prime}$-end of the Tyl RNA approximately corresponded to the locations of the HIV-1 RNA dimerization initiation/linkage and packaging sequences (Skripkin et al. 1994; Clever et al. 1996; Laughrea and Jette 1996; Sakuragi et al. 2003). The short length of the Ty1 CUCCUC sequence is similar to the HIV-1 dimerization initiation site or "kissing loop" (GCGCGC and GAGCUC for the MAL and LAI strains, respectively) (Skripkin et al. 1994; Clever et al. 1996; Laughrea and Jette 1996). However, the HIV-1 "kissing loop" is palindromic, while the Ty1 CUCCUC sequence is not. In hopes of finding the reverse complement of the Tyl CUCCUC sequence, we scanned the rest of the mini-Ty1-HIS3 RNA. Surprisingly, we identified two perfect reverse complements (GAGGAGA) of the extended UCUCCUC sequence in the LTRs (Fig. 4). This GAGGAGA sequence is located at the extreme $5^{\prime}$-end of the repeated (R) sequence of the Tyl RNA, one at the $5^{\prime}$-end and a second near the $3^{\prime}$-end of the mini-Ty1-HIS3 RNA. Seven mini-Ty1-HIS3 elements with single-base mutations within the $5^{\prime}$-GAGGAGA sequence were identified as transposition-deficient in the original $5^{\prime}$-region screen, again sig-

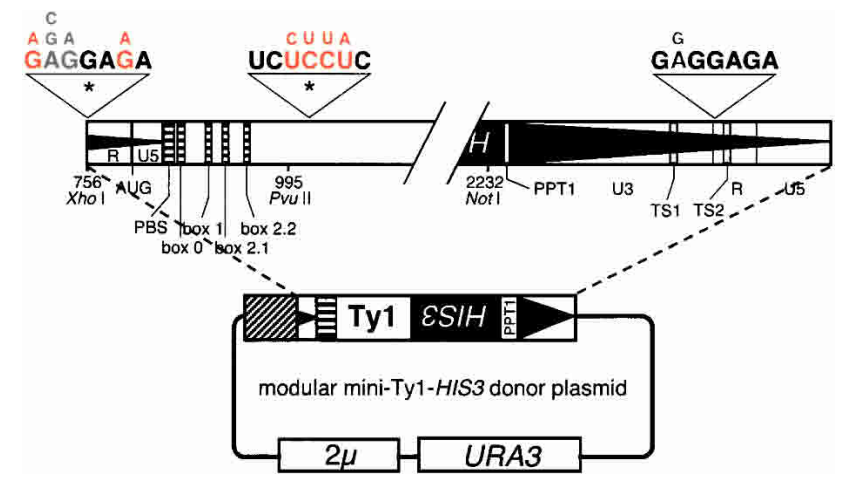

FIGURE 4. Summary of mutations within $5^{\prime}$-GAGGAGA, $5^{\prime}$-UCUC CUC, and 3'-GAGGAGA regions that reduced mini-Ty1-HIS3 transposition. Sequence in large gray type indicates single-base mutations on a transposition-deficient mini-Ty1-HIS3 element isolated during the original 5' - and $3^{\prime}$-region screens. Nucleotides in large orange type signify subcloned single-base mutations that were retested and demonstrated decreased transposition. Bases in small gray or orange type denote the mutant nucleotides identified at the position of the mutation. $\left(^{*}\right)$ Two clusters of mutations were not previously known to be required for transposition. nificantly greater than predicted by random distribution. Of the seven, two were confirmed by subcloning and retesting transposition (Fig. 4, indicated in orange and gray). However, one mini-Ty1-HIS3 element with a single-base mutation in the $3^{\prime}$-GAGGAGA sequence showed reduced transposition in our original screen of the $3^{\prime}$-region (Fig. 5, indicated in gray). These results suggest that the UCUC CUC sequence might interact with either of the GAGGAGA sequences within the $\mathrm{R}$ regions, and that such an interaction could be required for efficient transposition of the miniTy1-HIS3 element.

\section{5'-GAGGAGA and UCUCCUC interaction required for transposition}

The fact that the $5^{\prime}$-GAGGAGA corresponds to the extreme $5^{\prime}$-terminus of the Tyl RNA complicates analysis and interpretation. Mutation of this sequence could inhibit RNA expression or extension of minus-strand reverse transcription following minus-strand strong-stop DNA (-sssDNA) transfer. Therefore, we designed new mutations within the last three nucleotides of the GAGGAGA sequence to minimize possible effects on RNA expression, -sssDNA elongation, and codon preservation for testing the mutations in full-length Ty1 elements.

To test whether the interaction between the GAGGAGA and UCUCCUC sequences within the Tyl RNA is required for efficient transposition, we generated modular mini-Ty1HIS3 donor plasmids containing combinations of singleand double-base mutations within the GAGGAGA and UCUCCUC sequences. Transposition of these mutant mini-Ty1-HIS3 elements was assayed in the presence of the helper plasmid in a rad52 $\Delta$ strain to minimize background from homologous recombination. The single-base mutations were designed based on one of the mutations identified during the original $5^{\prime}$ screen as well as codon preservation (Fig. 5A). Mutation of $U$ to $C$ in the UCUCCUC sequence decreased transposition, as did mutation of $A$ to $G$ in the $5^{\prime}$-GAGGAGA sequence (Fig. 5B). However, the same $A$ to $G$ mutation in the 3 -GAGGAGA sequence did not affect transposition of the mini-Ty1-HIS3 element. Moreover, combining the $\mathrm{U}$ to $\mathrm{C}$ mutation in the UCUC CUC sequence with the A to $G$ mutation in the $5^{\prime}-G \bar{A} G$ GAGA sequence, thus restoring perfect complementarity, rescued transposition of the mini-Tyl-HIS3 element to wild-type levels. In contrast, restoration of complementarity by combining the $\mathrm{U}$ to $\mathrm{C}$ mutation in the UCUCCUC sequence with the $A$ to $G$ mutation in the $3^{\prime}$-GAGGAGA sequence did not rescue transposition of the mini-Ty1- $\bar{H} I S 3$ element.

The double-base mutations were designed based on mutations identified during the original 5' screen, codon preservation (allowing testing in a "native" Gal-Tyl context), and maintenance of the $\mathrm{G} / \mathrm{C}$ content of the interacting sequences (Fig. 5A). Mutation of the UC to AG in the UCUC 




FIGURE 5. Base-pairing between two Tyl sequences near the $5^{\prime}$-end of the RNA is required for efficient transposition. (A) Cartoon indicating the positions of the mutated Tyl sequences. Expressed Tyl RNAs (black wavy lines) containing combinations of single-base (boxed black letter on white background) or double-base (boxed white letters on black background) mutations (positions indicated by the black X). (R) The sequences are found within the repeated region of the RNA; $\left(^{*}\right)$ indicates the location of the UCUCCUC sequence, downstream of the PvuII site in the Tyl element. Transposition of $(B)$ modular mini-Tyl-HIS3 and $(C)$ full-length Tyl-mhis3AI elements containing combinations of mutations that were engineered into the UCUCCUC sequence as well as the reverse complementary sequences (GAGGAGA) within the R regions located at the ends of the Tyl RNA. Transposition was assayed under repressing (glucose medium) and inducing (galactose medium) conditions at the indicated temperatures. The mini $\Delta$, pECB5K1, and RT-, pGTy1-H3-mhis3AI DD-DE (Uzun and Gabriel 2001), constructs contain transposition-deficient Tyl elements. Transposition frequencies from separately performed quantitative transposition assays are indicated as the percentage of wild type in white lettering.

CUC sequence decreased transposition, as did mutation of the GA to $\mathrm{CU}$ in the $5^{\prime}$-GAGGAGA sequence (Fig. 5B). However, the same GA to $\mathrm{CU}$ mutation in the $3^{\prime}-\mathrm{GAG}$ GAGA sequence did not affect transposition of the miniTy1-HIS3 element. Moreover, combining the UC to AG mutation in the UCUCCUC sequence with the GA to CU mutation in the $5^{\prime}$-GAGGAGA sequence, thus restoring perfect complementarity, rescued transposition of the miniTy1-HIS3 element to wild-type levels. Experiments analyzing potential interactions with the $3^{\prime}-\mathrm{R}$ sequence came to very different conclusions (Fig. 5B). Restoration of complementarity by combining the UC to AG mutation in the UCUCCUC sequence with the GA to CU mutation in the 3'-GAGGAGA sequence did not rescue transposition of the mini-Ty1-HIS3 element.

Because the double-base mutations are silent changes relative to the Gag amino acid sequence, the combinations of double-base mutations could be moved into a full-length Ty1-mhis3AI element contained within the pECB9C donor plasmid. The transposition phenotype of these helper-independent mutant Tyl-mhis3AI elements was then tested. The resulting transposition phenotypes of the mutant fulllength Tyl-mhis $3 A I$ elements mirrored the phenotypes of the mutant mini-Ty1-HIS3 elements (Fig. 5, cf. B and C). Only the presence of complete reverse complementarity between the 5'-GAGGAGA and UCUCCUC sequences resulted in efficient transposition. Moreover, increasing the temperature during Tyl induction and transposition, possibly further reducing the stability of the already strained interactions between the mutated 5'-GAGGAGA and UCUCCUC sequences, decreased the transposition frequency even further (Fig. 5C). These results indicate that these two sequences must interact during retrotransposition. Whether the interaction between the 5'-GAGGAGA and UCUCCUC sequences is intramolecular or intermolecular is not addressed by the above experiments.

\section{Mutated 5'-GAGGAGA/UCUCCUC interaction reduces $\mathrm{cDNA}$ production}

The restoration of transposition to Ty1-mhis $3 A I$ elements with combined compensatory mutations in the Tyl RNA suggests that Tyl RNAs with mutations in these regions are expressed and packaged well. To directly address the question of whether the mutant Ty1-mhis3AI RNAs are expressed to the same level as wild type, total RNA was isolated from cells expressing the Tyl-mhis $3 A I$ elements. RNA blot analysis revealed that the steady-state levels of Ty1mhis3AI transcript relative to actin for the $5^{\prime}$-GAGGAGA and UCUCCUC mutants were slightly lower than for wildtype Ty1-mhis3AI RNA, and the compensatory double-mutant RNA levels were similar to wild type (Fig. 6A). While increasing the temperature during Tyl induction and transposition, possibly further reducing the stability of the already strained interactions between the mutated 5'-GAG GAGA and UCUCCUC sequences, decreased the transposition frequency (Fig. 5C), it did not alter the steady-state levels of Tyl-mhis $3 A I$ transcript relative to actin, which persisted during the higher-temperature induction albeit at diminished levels compared to induction at lower temperature. These data indicate that the mutant Ty1-mhis3AI tran- 
A

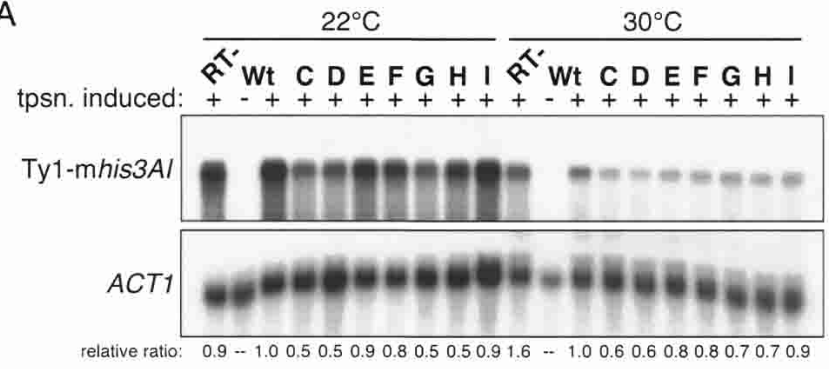

B

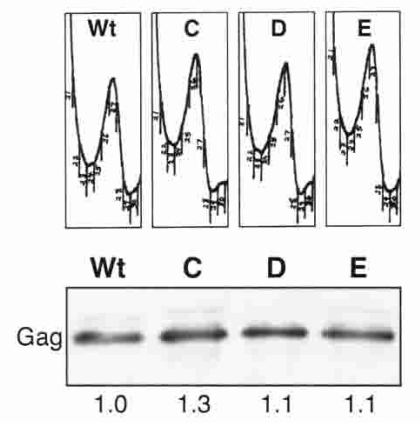

C

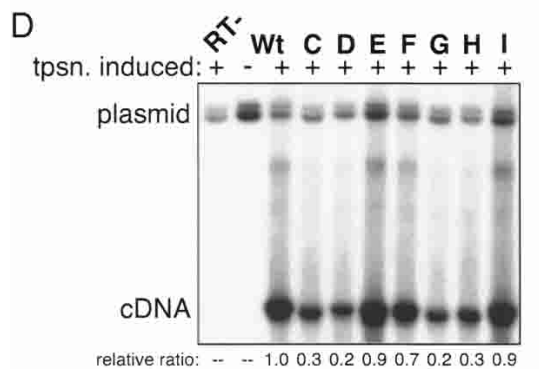

FIGURE 6. Characterization of Ty1 RNA, VLPs, and cDNA produced from mutant full-length Ty1-mhis3AI elements. (A) RNA blot comparing the steady-state expression levels of wild-type (Wt) and mutant Ty1-mhis3AI elements (double-base mutants C-I from Fig. 5). ACT1 hybridization was used as a loading control. RNA levels were assayed under repressing (-, glucose medium) and inducing $(+$, galactose medium) conditions at the indicated temperatures. ( $B$, upper panels) Chart tracings of VLP peaks isolated from cells expressing wild-type (Wt) and mutant Tyl-mhis3AI derivatives (double-base mutants C-E from Fig. 5). Fractionation of the VLP gradients was monitored by the absorbance at $254 \mathrm{~nm}$. In numerous similar experiments, VLP peaks are absent for cells lacking a pGTyl element or grown under Ty1mhis3AI-repressing conditions. (B, lower panel) Immunoblot of the peak VLP-containing gradient fractions using anti-Gag antibody. Immunoblotting was performed as described (Bolton et al. 2002). The amount of Gag protein detected for mutant relative to wild-type VLPs is indicated. (C) RNA blot comparing the his3AI-marked Tyl RNA isolated from VLPs produced by wild-type (Wt) and mutant Tylmhis $3 A I$ elements. Total RNA isolated from cells expressing the wildtype Ty1-mhis3AI element was used as a control for specific packaging of Ty1-mhis3AI RNA. ACT1 and his3AI hybridization signals detected in the total RNA sample are absent from RNA samples isolated from the various VLPs. $(D)$ Production of HIS3-marked Ty1 cDNA in cells expressing the Tyl-mhis3AI elements. The HIS3 probe hybridized to Tyl cDNA as well as to the his3AI-marked pGTyl-H3 donor plasmid (internal loading control). Tyl cDNA production was assayed under repressing (-, glucose medium) and inducing (+, galactose medium) conditions at $22^{\circ} \mathrm{C}$. Similar results were observed for Tyl cDNA production at $30^{\circ} \mathrm{C}$. scripts are expressed at levels similar to the wild-type RNA, suggesting that the mutations affect a post-transcriptional step in transposition.

To discern whether the transposition defect of the mutant Ty1-mhis3AI elements resulted from altered VLP assembly/packaging, we isolated VLPs from wild-type cells expressing the mutant Ty1-mhis3AI elements. During the fractionation of the VLP-containing gradients, the absorbance at $254 \mathrm{~nm}$ of each gradient and the abundance of Gag protein were monitored. The yields of VLPs and Gag protein present in the peak fractions were nearly identical for particles isolated from cells containing wild-type and all tested mutant Ty1-mhis3AI elements (Fig. 6B). Moreover, the VLPs isolated from cells expressing mutant Ty1mhis $3 A I$ elements contained similar levels of Ty1-mhis $3 A I$ RNA as VLPs isolated from cells expressing a wild-type Ty1-mhis3AI element (Fig. 6C). Clearly, wild-type and mutant Ty1-mhis3AI elements produce similar amounts of VLPs. These VLPs contain similar levels of RNA, suggesting that the mutant RNAs are packaged efficiently.

To determine whether reverse transcription of the mutant Ty1-mhis $3 A I$ elements was completed, we measured the amounts of Ty1-HIS3 cDNA produced in cells following induction of Tyl expression (Fig. 6D). Interestingly, the steady-state levels of cDNA produced relative to Ty1mhis $3 A I$ donor plasmid were significantly reduced whenever the complementarity of the 5'-GAGGAGA and UCUC CUC sequences was disrupted. Restoration of complete complementarity rescued cDNA yield to wild-type levels. These findings clearly parallel the transposition phenotypes observed for the wild-type and mutant Ty1-mhis3AI elements. These data together with the steady-state expression data strongly suggest that disrupting the 5'-GAGGAGA and UCUCCUC interaction affects transposition by inhibiting a step(s) between VLP assembly and the completion of reverse transcription such as formation of a Tyl RNA structure that is required for efficient reverse transcription.

\section{Intra- or intermolecular interactions?}

We performed a set of experiments designed to test whether the observed interactions between the 5'-GAGGAGA and internal UCUCCUC sequences were intra- or intermolecular (Fig. 7A). To accomplish this, we first used a trans complementation approach in which various Tyl-neo elements serve as helpers to transpose Tyl-mhis $3 A I$ elements, and transposition frequency of the various Tyl-mhis $3 A I$ elements is assayed (Fig. 7B, heavy black wavy line). A Tylmhis $3 A I$ element containing mutations in either the $5^{\prime}$ GAGGAGA or UCUCCUC sequences transposes poorly even in the presence of a full-length wild-type Ty1-neo element (Fig. 7B, light gray wavy lines). However, the presence of compensatory mutations at the appropriate positions in the full-length Tyl-neo element should rescue transposition of the mutant Ty1-mhis $3 A I$ elements to wild- 
A

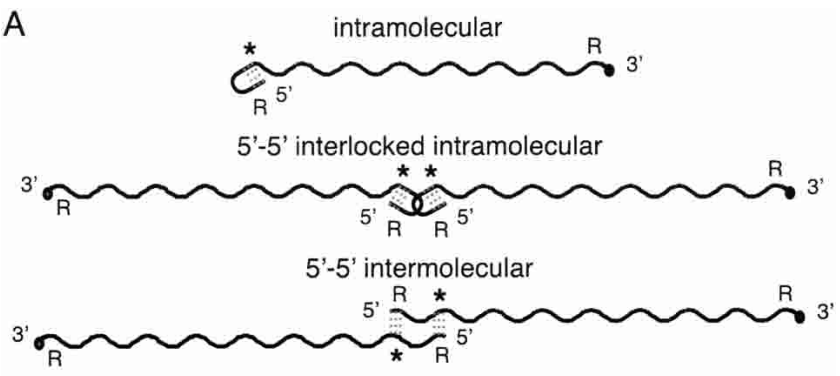

B

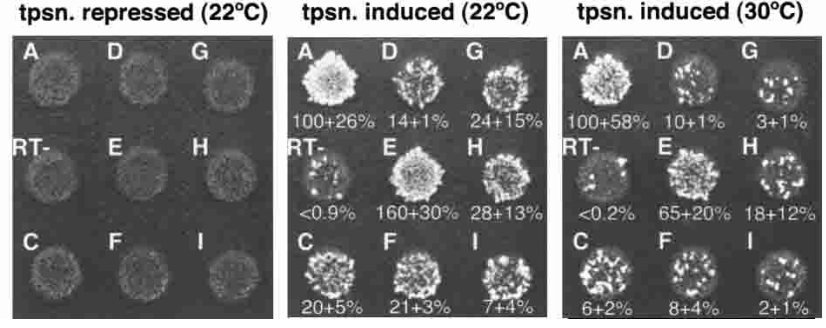

FIGURE 7. Intra- or intermolecular interactions? ( $A$ ) Proposed models for the functional interaction between $5^{\prime}$ Tyl RNA sequences. The black wavy lines represent Tyl RNA (dot at $3^{\prime}$-end), and the gray dashed lines indicate the base-pairing interactions between the $5^{\prime}$ GAGGAGA and UCUCCUC sequences. (B) Analysis of intra- or intermolecular interactions using a his3AI-marked Tyl readout in combination with various Tyl-neo elements expressed from a separate plasmid. See text for details. (C) Transposition of full-length wild-type (combination A) or double-base mutant (combinations C-I) Ty1mhis3AI elements (lower black wavy lines) in combination with wildtype (combinations A-E) or double-base mutant (combinations F-I) Tyl-neo elements (upper gray wavy lines). Transposition was assayed under repressing (glucose medium) and inducing (galactose medium) conditions at the indicated temperatures. Transposition frequencies of Ty1-mhis $3 A I$ elements from separately performed quantitative transposition assays are indicated as the percent of wild-type/wild-type (combination A) in white lettering.

type frequencies, but only if the compensatory mutations allow the two mutant RNAs to interact intermolecularly. In particular, combinations $\mathrm{G}$ and $\mathrm{H}$ are predicted to show elevated transposition relative to the corresponding single mutant controls $\mathrm{C}$ and $\mathrm{D}$ if intermolecular interactions can occur freely under these experimental conditions. This was not observed (Fig. 7C), supporting the idea that these sequences interact intramolecularly, which is supported by the efficient transposition of combination $\mathrm{E}$.
To confirm that the failure to complement in trans was not due to unequal expression or mixing of the two plasmids, we used a double mini-Tyl system in which a single donor plasmid was used to simultaneously express a pair of inverted and differentially marked mini-Tyl elements (Fig. 8A). Transposition of the HIS3-marked mini-Tyl element (Fig. 8B, black wavy lines) was assayed when expressed in the presence of both wild-type and mutant miniTy1-TRP1 elements (Fig. 8B, gray wavy lines). A failure of combined mutant GAGGAGA and UCUCCUC sequences to restore transposition was also seen using this approach (Fig. 8C).

A

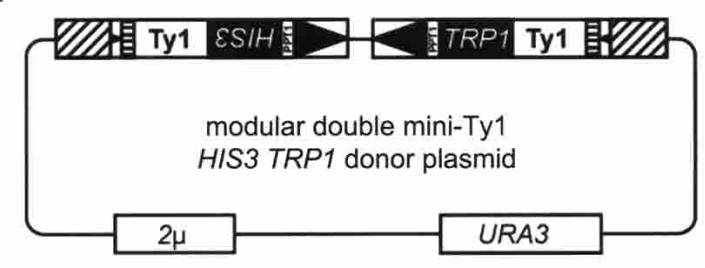

B

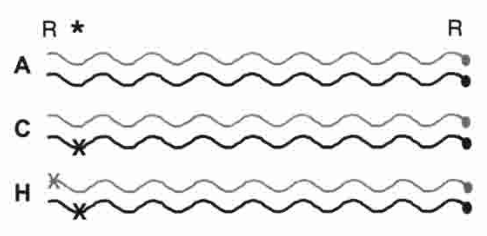

C
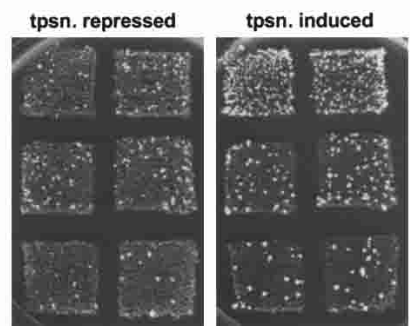
A: WT (HIS3)
plus WT (TRP1)
$100 \pm 26 \%$
C: CUCU mutant
(HIS3) plus WT (TRP1)
$18 \pm 15 \%$
H: CUCU mutant (HIS3)
plus GAGA mutant (TRP1) $8 \pm 6 \%$

FIGURE 8. Intra- or intermolecular interactions using the modular mini-Ty1 transposition system? (A) Structure of the modular double mini-Ty1-HIS3 TRP1 donor plasmid. As described in Figure 1, the inducible GAL1 promoter (striped box), the pBR322 sequences (black lines), and yeast sequences (boxes) are indicated. The HIS 3 and TRP1 marker genes have the opposite transcriptional orientation as their mini-Tyl element. The helper plasmid shown in Figure 1A was also present in cells to supply Tyl proteins in trans. (B) Analysis of intermolecular interactions using a HIS3-marked, Tyl readout (black wavy lines) in combination with various Ty1-TRP1 elements (gray wavy lines) expressed from the same plasmid. See text for details. (C) Transposition of full-length wild-type (combination A) or double-base mutant (combinations $\mathrm{C}$ and $\mathrm{H}$ ) mini-Tyl-HIS3 elements (lower black wavy lines) in combination with wild-type (combinations A and C) or double-base mutant (combination $\mathrm{H}$ ) mini-Ty1-TRP1 elements (upper gray wavy lines). Transposition was assayed under repressing (glucose medium) and inducing (galactose medium) conditions. Transposition frequencies of mini-Ty1-HIS3 elements from separately performed quantitative transposition assays are indicated as the percent of wild-type/wild-type (combination A). 


\section{DISCUSSION}

Here, we report the development and use of a genetic screening strategy involving the mutagenesis of mini-Ty1HIS3 elements and subsequently assaying their transposition frequency. By this strategy, only mutations in cis-acting sequences should result in a transposition defect, because all Tyl proteins are supplied in trans from the helper plasmid. This reasonable assumption held true based on the abundance of mutations that mapped to known cis elements like the GAL1 TATA-box, the PBS region, and PPT1, and the lack of recovery of AUG and nonsense mutations within the truncated $G A G$ coding sequence.

We have demonstrated genetically that interactions within Ty1 RNA, specifically between the 5'-GAGGAGA and UCUCCUC sequences, are required for Tyl transposition. For both the modular mini-Ty1-HIS3 element and the full-length Tyl element, we have shown that nucleotide changes disrupting Watson-Crick base pairs between these two Ty1 RNA sequences reduce Ty1 transposition 10-20fold. Compensatory mutations restoring complete complementarity between these two Tyl RNA sequences rescue Tyl transposition to wild-type frequencies. Moreover, mutation of the 5'-GAGGAGA and UCUCCUC sequences slightly decreased the steady-state levels of Ty1-mhis $3 A I$ RNA and did not appear to inhibit packaging of these RNAs into VLPs, but reduced production of Ty1-mhis $3 A I$ cDNA by threefold to fivefold.

Retroviruses and presumably retrotransposons package two copies of their RNA genome into virion particles by a noncovalent, multistep process, which includes RNA dimerization. In general, self-complementary dimer initiation sites interact intermolecularly to form a kissing-loop complex, which is transformed into a stable extended duplex by spreading the intermolecular interaction to neighboring bases (Paillart et al. 2004). The classic dimer initiation sites demonstrated for HIV-1, HIV-2, and avian retroviruses are short self-complementary sequences (Bieth et al. 1990; Darlix et al. 1992; Laughrea and Jette 1994; Skripkin et al. 1994; Clever et al. 1996; Fosse et al. 1996; Dirac et al. 2001; Lanchy and Lodmell 2002). Notably, the palindromic dimer initiation sites in HIV-1 provide a nucleation point for RNA dimerization, but additional RNA sequences are known to play roles in virion RNA dimerization (Clever et al. 1996; Hill et al. 2003; Russell et al. 2003; Sakuragi et al. 2003). HIV-1 mutants with altered dimer initiation sites also have strand-transfer defects during reverse transcription (Paillart et al. 1996a; Shen et al. 2000). For MoMuLV RNA, two hairpins that form intermolecular interactions and two additional stem-loops that form intermolecular kissing-loop interactions initiate dimerization, while longer self-complementary sequences are believed to stabilize the dimer (Tounekti et al. 1992; Oroudjev et al. 1999; Kim and Tinoco 2000; Ly and Parslow 2002). Meanwhile, the sites of dimer initiation and the detailed mechanisms of RNA dimerization and packaging re- main poorly known for most retroviruses and retrotransposons.

The required interaction between the $5^{\prime}$-GAGGAGA and UCUCCUC sequences could be either intramolecular or intermolecular (Fig. 7). Intermolecular interaction models are attractive for several reasons. (1) The genomic RNA in Ty1 VLPs is reportedly dimeric (Feng et al. 2000). (2) The absence of a classic "kissing-loop" motif (Clever et al. 1996; Laughrea and Jette 1996; Paillart et al. 1996b, 2004) near the 5 '-end of the Tyl RNA suggests that some other dimerization initiation site is needed. (3) Base-pairing interactions between these two short sequences of the Tyl RNA would allow the formation of noncovalently linked dimers. However, our experiments to date have not supported such an intermolecular model. This could be because we have not performed the experiment under appropriate experimental conditions, or alternatively, it could be that Ty1 RNA forms an interlocked dimer via intramolecular interactions (Fig. 7A). It is also possible that a higher-order RNA structure, which is preferentially packaged into VLPs, is not sufficiently crippled by single-base changes, or other, yet to be characterized mutations identified during our $5^{\prime}$-region screen may inhibit formation of such a structure. Further study will be needed to clearly identify the "packaging signal" for Ty1. Our experiments designed to distinguish between potential intra- and intermolecular interactions of the GAGGAGA and UCUCCUC sequences clearly implicate an intramolecular interaction. It is important to point out that our experiments do not rule out an additional intermolecular interaction of the GAGGAGA and UCUCCUC sequences; for example, there could be multiple conformations of the RNA required to effect transposition that include both intra- and intermolecular interactions.

The intramolecular interaction between the $5^{\prime}$-GAG GAGA and UCUCCUC sequences may function during reverse transcription, possibly to stabilize a preferred RNA structure. For Tyl, the cellular $\mathrm{RNA}_{\mathrm{i}}{ }^{\mathrm{Met}}$, which likely forms an integral part of this structure, is extended by reverse transcriptase (Chapman et al. 1992). The secondary structure model of the 1-440 Ty1 RNA with the 1-75 cellular

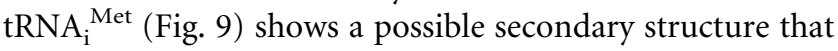
maintains the intramolecular interaction between the $5^{\prime}$ GAGGAGA and UCUCCUC sequences. The model, which represents thermodynamically the most stable structure $(\Delta G=-139.7 \mathrm{kcal} / \mathrm{mol})$, was generated using mfold 3.1 software (Mathews et al. 1999; Zuker 2003). Notably, inclusion of the 1-75 cellular tRNA ${ }_{i}{ }^{\text {Met }}$ during folding increases the overall stability of the folds without altering the structures of the most stable folds, except at the expected PBS, box 0, box 1, and box 2.1 regions (nucleotides 91-174) of the Tyl RNA. Similar secondary structures, which favor interaction of the GAGGAGA and UCUCCUC sequences, were obtained when Ty1 RNAs of 270-580 nt were folded. Interestingly, complementarity between the extreme 5 '-end 


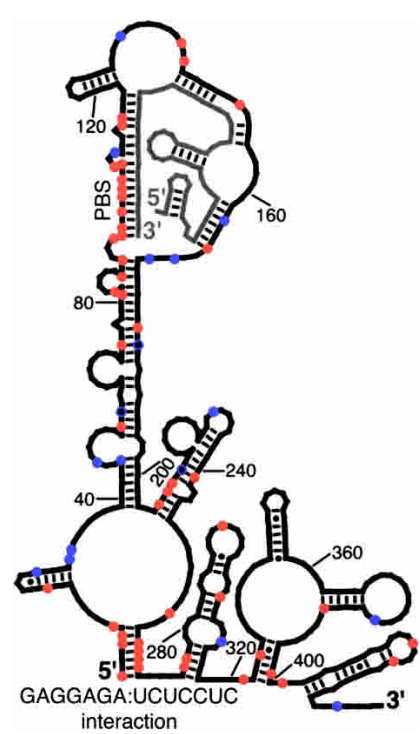

FIGURE 9. Proposed secondary structure model for the Tyl RNA. The model was constructed using the mfold program, version 3.1 (http://www.bioinfo.rpi.edu/applications/mfold/old/rna) (Mathews et al. 1999; Zuker 2003) and represents the most stable secondary structure returned for the 1-440 Tyl RNA and the 1-75 cellular tRNA ${ }_{i}{ }^{\text {Met }}$ $(\Delta G=-139.7 \mathrm{kcal} / \mathrm{mol}$ ) that also agrees with the mutagenesis analysis (see the Results). The cellular tRNA ${ }_{i}^{\text {Met }}$ (gray lines) was folded with the Tyl RNA (black lines) and is shown interacting with the PBS (nucleotides 95-104), box 0 (nucleotides 110-116), box 1 (nucleotides 144-149), and box 2.1 (nucleotides 162-168). The short black lines represent Watson-Crick base pairs, and the filled black circles represent G:U base pairs. The proposed intramolecular interaction between 5'-GAGGAGA (nucleotides 1-7) and UCUCCUC (nucleotides 264270) sequences and the positions of single nucleotide changes in the 1-440 Ty1 RNA and their effect on transposition are indicated. Filled orange circles depict mutated bases that decreased transposition, while mutations that did not affect transposition are in blue. The black-filled blue circles represent mutated bases in which an A:U base pair was replaced with a $\mathrm{G}: \mathrm{U}$ base pair.

and a sequence $360-370 \mathrm{nt}$ into the Tf1 retrotransposon transcript has been implicated in priming Tf1 reverse transcription (Levin 1995). It is similar in position compared to the pair of sequences we observed although the Ty1 sequences are only 7 bp long, whereas the Tf1 sequences are 11 bp long. In both Tf1 (Lin and Levin 1997) and Ty1 (Fig. 9), an extensive network of base-pairing interactions adjacent to these sequences can be drawn. It is possible that these interacting sequences nucleate the formation of a large, complex RNA structure that facilitates RNA packaging and priming of reverse transcription.

The finding that specific interactions are required for efficient dimerization, packaging, and reverse transcription of several LTR retrotransposons and retroviruses suggests common mechanisms for multiple steps of retroelement replication. Further structure and function studies are necessary to determine the higher-order structural similarity of Ty1 RNA to other retroelements, especially retroviruses.

\section{MATERIALS AND METHODS}

\section{Strains and media}

The strains used in this study were JB740 (MAT $\alpha$ his3 200 leu2 $\Delta 1$ ura3-167) and yEB102C (JB740 with rad52A :: natMX4). Media were prepared as described (Sherman et al. 1986).

\section{Plasmid constructions}

The modular mini-Ty1-HIS3 donor plasmid, pECB3K, was generated by replacing the HpaI-NotI fragment $(4.8 \mathrm{~kb})$ of pJEF1262 (Monokian et al. 1994) with the HIS3 gene in the opposite transcriptional orientation as the Tyl element. The PCR product was generated by amplifying the HIS3 gene contained in pRB328 using primers JB2285 (5'-ATAGAAGCGGCCGCGATCCTCTAGTA CACTCTATATTTTT- $\left.3^{\prime}\right)$ and JB2286 (5'-ACCTAAGTTAACG GCCGACCTAGGTGCAGCTTTAAATAATCGGTGTCA-3'). The mhis3AI version of pECB3K, pECB4B, was constructed similarly, except the mhis $3 A I$ gene PCR product was amplified from pGTy1H3-mhis3AI (Curcio and Garfinkel 1991). The mutant mini-Ty1HIS3 plasmid, pECB5K1 (minis), resulted from removal of the critical PvuII-HpaI fragment $(0.3 \mathrm{~kb})$ (Xu and Boeke 1987) of pECB3K. The helper plasmid, pECB2B2, was constructed by removing the BglII-NcoI fragment $(0.5 \mathrm{~kb})$ of the $2 \mu$ LEU2 backbone pGal-Ty1-H3, pX87 (H. Xu and J. Boeke, unpubl.), to delete the PPT1 sequence and the entire 3 '-LTR, and replacing the XhoIHind III fragment $(4.4 \mathrm{~kb})$ with that of pKC66 (Chapman et al. 1992), which contains a multiply mutated PBS sequence. These modifications render the helper Tyl element unable to transpose, while allowing Tyl protein overexpression. The full-length Ty1mhis3AI plasmid, pECB9C, was generated by inserting the EagI fragment $(1.0 \mathrm{~kb})$ of $\mathrm{pECB} 4 \mathrm{~B}$ containing the mhis $3 A I$ gene into the NotI site of pJEF1262. The double mini-Ty1 plasmid was constructed by insertion of a mini-Ty1-TRP1 element ( $2.7 \mathrm{~kb})$, PCRamplified from pJEF1202 (Xu and Boeke 1990), into the SalI site of plasmid pECB3K. Mutant plasmids were constructed in the same manner.

Single- and double-base change mutations were made in the Xhol-HpaI fragment $(0.6 \mathrm{~kb})$ or the NotI-BamHI fragment $(0.6$ $\mathrm{kb}$ ) of pECB3K by site-directed mutagenesis of each fragment in the pBluescript II SK vector (Stratagene) backbone. Mutations were verified by sequencing the entire fragment. Mutant fragments were then returned to the $\mathrm{pECB} 3 \mathrm{~K}$ vector. The double-base change mutations were introduced into the full-length Tyl-mhis3AI vector, pECB9C, by replacing the HpaI-NotI $(0.9 \mathrm{~kb})$ fragment of pECB3K with the HpaI-NotI (4.8 kb) fragment of pECB9C. The full-length Ty1-mhis $3 A I$ elements of the $2 \mu$ URA3 backbone pGalTy1-H3-mhis3AI, pECB9C, and double-base change derivatives, were converted to the $2 \mu$ LEU2 backbone pGal-Ty1-H3-neo, pECB332A, and double-base change derivatives. First, the KpnIBamHI (3.6 kb, mhis3AI gene) fragment of the pECB9C derivatives was replaced with the KpnI-BamHI ( $3.6 \mathrm{~kb}$, neo gene) fragment of pJEF1105 (Boeke et al. 1988b), and then the AatII-NcoI (6.6 kb, pGal-Ty1) fragment of the $2 \mu$ LEU2 backbone pGal-Ty1$\mathrm{H} 3$, pX87 (H. Xu and J. Boeke, unpubl.), was replaced with the AatII-NcoI (7.6 kb, pGal-Tyl-neo) fragment of the resulting $2 \mu$ URA3 backbone pGal-Ty1-H3-neo constructs. 


\section{Mutagenic polymerase chain reaction (PCR) and gapped plasmid repair}

Mutagenic amplification of the XhoI-HpaI and the NotI-BamHI regions of pECB3K with $\sim 200$ bp of flanking sequence at each end were performed using primers JB2456 (5'-GCCCCACAAAC CTTCAAATG-3') with JB2457 (5'-CTAGCAGAATTACCCTC CAC-3') and JB2460 (5'-GCTCTGTCATCTTTGCCTTC3') with JB2642 (5'-GCCGCCGCAAGGAATGGTG-3'), respectively. In all, 96 mutagenic PCR reactions $(50 \mu \mathrm{L}$ each) contained $1.5 \mathrm{mM}$ $\mathrm{MgCl}_{2}, 100 \mu \mathrm{M} \mathrm{MnCl}_{2}, 100 \mu \mathrm{M}$ dNTP, 13 ng of pECB3K, $0.2 \mathrm{mM}$ each primer, and 2.5 units of AmpliTaq DNA polymerase (Roche Molecular Biochemicals). Reactions were performed in a PerkinElmer 9600 PCR machine (PerkinElmer) using the following method: $95^{\circ} \mathrm{C}$ for $5 \mathrm{~min}, 95^{\circ} \mathrm{C}$ for $1 \mathrm{~min}, 53^{\circ} \mathrm{C}$ for $1 \mathrm{~min}, 72^{\circ} \mathrm{C}$ for $1 \mathrm{~min}$ ( 30 cycles), and a final 5 -min extension at $72^{\circ} \mathrm{C}$. The above conditions were found to generate 1 misincorporation per $800 \mathrm{bp}$ polymerized or $\sim 1$ misincorporation per PCR product. The mutation frequency was determined by sequencing the mutagenized 5 '-region of modular mini-Ty1-HIS3 donor plasmids recovered from six yeast colonies that were not transposition-deficient. Unexpectedly, the same PCR conditions resulted in a much higher mutation frequency during the mutagenesis of the $3^{\prime}$-region. We strongly believe that the frequency discrepancies resulted from a miscalibrated PCR machine during the $3^{\prime}$ mutagenic screen. We added 10 units of DpnI to each PCR reaction, and the reactions were incubated at $37^{\circ} \mathrm{C}$ for $2 \mathrm{~h}$, then at $80^{\circ} \mathrm{C}$ for $20 \mathrm{~min}$ to digest the pECB3K template. To maximize product diversity, groups of eight PCR reactions were combined into 12 pools, each subsequently subjected to phenol/chloroform extraction and ethanol precipitation. The mutagenized PCR products were then diluted in TE (10 mM Tris- $\mathrm{HCl}$ at $\mathrm{pH} 8$ and $1 \mathrm{mM}$ EDTA) to a final concentration of $60 \mathrm{ng} / \mu \mathrm{L}$.

Gapped modular mini-Ty1-HIS3 donor plasmids were generated by digesting $\mathrm{pECB} 3 \mathrm{~K}$ with either $\mathrm{XhoI}$ and HpaI (5'-end mutagenesis) or NotI and BamHI ( $3^{\prime}$-end mutagenesis). Digests were subjected to phenol/chloroform extraction and ethanol precipitation. The nucleic acid pellets were then diluted in TE to a final concentration of $100 \mathrm{ng} / \mu \mathrm{L}$.

\section{Transformation and transposition assays}

Mutagenized PCR products (300 ng) and gapped mini-Ty1-HIS3 plasmid (100 ng) were cotransformed at a mole ratio of 33 to 1 , respectively, into the JB740 yeast strain already containing the helper plasmid, pECB2B2. Yeast transformants containing the gap-repaired Tyl-HIS3 modular mini donor plasmid $(2 \mu$ URA3 backbone) and the helper plasmid ( $2 \mu$ LEU2 backbone) were grown on SC medium lacking histidine, leucine, and uracil (SCHis-Leu-Ura) with $2 \%$ glucose. After $3 \mathrm{~d}$ at $30^{\circ} \mathrm{C}$, yeast colonies were replica-plated to SC-His-Leu-Ura with $2 \%$ glycerol/ethanol and incubated at $30^{\circ} \mathrm{C}$ for $3 \mathrm{~d}$ to inhibit the growth of petite colonies. Yeast colonies were replica-plated to SC-His-Leu-Ura with $2 \%$ galactose and incubated at $22^{\circ} \mathrm{C}$ for $3 \mathrm{~d}$ to induce Tyl expression and transposition. The Tyl plasmids were shuffled out by growth on YPD at $30^{\circ} \mathrm{C}$ overnight followed by growth on $\mathrm{SC}$-His containing $1 \mathrm{~g} / \mathrm{L}$ of 5-fluoro-orotic acid (5-FOA) (Boeke et al. 1984) with $2 \%$ glucose at $30^{\circ} \mathrm{C}$ for $2 \mathrm{~d}$ (selective growth for cells containing a transposed copy of modular mini Ty1-HIS3).
Additional transposition assays performed on transformants containing the modular mini-Ty1-HIS3 donor or derivatives and the helper plasmids were performed as described previously, except patches or spots of cells were replica-plated, the glycerol/ ethanol plate was excluded, and induction of Ty1 expression and transposition with $2 \%$ galactose was for $3 \mathrm{~d}$ (strain JB740) or $4 \mathrm{~d}$ (strain yEB102C). Ty1-HIS3 transposition was assayed qualitatively, and SC-His+5-FOA plates were photographed.

Yeast transformants containing the Ty1-mhis $3 A I$ donor plasmid ( $2 \mu$ URA3 backbone), pECB9C, or derivatives were spotted onto SC-Ura with $2 \%$ glucose. After $2 \mathrm{~d}$ at $30^{\circ} \mathrm{C}$, yeast spots were replica-plated to similar medium with $2 \%$ galactose and incubated at $22^{\circ} \mathrm{C}$ or $30^{\circ} \mathrm{C}$ for $1.5 \mathrm{~d}$. The Tyl donor plasmid was then shuffled out by growth on YPD at $30^{\circ} \mathrm{C}$ overnight followed by growth on SC-His +5 -FOA with $2 \%$ glucose at $30^{\circ} \mathrm{C}$ for $2 \mathrm{~d}$ (selective growth for cells containing a transposed copy of Ty1mhis3AI). Tyl-mhis3AI transposition was initially assayed qualitatively, and SC-His+5-FOA plates were photographed. Transposition frequencies were determined for at least three independent transformants by scraping cells from spots on YPD plates into sterile water, plating various dilutions on SC+5-FOA and SCHis+5-FOA plates, and subsequently counting colonies.

Yeast transformants containing various combinations of a Ty1mhis3I donor plasmid ( $2 \mu$ URA3 backbone), pECB9C, or doublebase change derivatives, and a Ty1-neo donor plasmid $(2 \mu$ LEU2 backbone), pECB332A, or double-base change derivatives, were spotted onto SC-Ura with $2 \%$ glucose. After $2 \mathrm{~d}$ at $30^{\circ} \mathrm{C}$, yeast spots were replica-plated to similar medium with $2 \%$ galactose and incubated at $22^{\circ} \mathrm{C}$ or $30^{\circ} \mathrm{C}$ for $2 \mathrm{~d}$ (strain JB740) or $3 \mathrm{~d}$ (strain yEB102C). The Tyl donor plasmids were then shuffled out as described above. SC-His+5-FOA plates were photographed, and Ty1-mhis $3 A I$ transposition frequencies were determined as described above.

Yeast transformants containing the double mini-Tyl donor plasmid ( $2 \mu$ URA3 backbone) and helper plasmid ( $2 \mu$ LEU2 backbone) were spotted onto SC-Ura-Leu with $2 \%$ glucose. After $3 \mathrm{~d}$ at $30^{\circ} \mathrm{C}$, yeast spots were replica-plated to an SC-Ura-Leu with either $2 \%$ glucose or $2 \%$ galactose and incubated at $22^{\circ} \mathrm{C}$ for $4-10$ $\mathrm{d}$. Both plasmids were then shuffled out by replica-plating onto YPD medium and growth at $30^{\circ} \mathrm{C}$ for $2 \mathrm{~d}$, followed by selection on $\mathrm{SC}-\mathrm{His}+5-\mathrm{FOA}$ at $30^{\circ} \mathrm{C}$ for $3 \mathrm{~d}$. SC-His +5 -FOA plates were photographed and Ty1-HIS3 transposition frequencies determined as described above.

\section{Additional screening of primary mutants}

During screening of the $5^{\prime}$-region, it became apparent that many of our transposition-deficient primary isolates were mutant for less interesting reasons. Patches were retested for transposition as described above. For the $5^{\prime}$ - and $3^{\prime}$-region primary mutants, $15 \%$ and $30 \%$, respectively, of the mutants transposed better than $\operatorname{mini} \Delta$ upon retesting; these were discarded. General growth of mutant colonies was also tracked throughout transposition retest, and slow growers (relatively few) were eliminated from further analysis. Segregation or the ability of cells to lose the modular mini-Ty1-HIS3 donor plasmid was tested by growth on YPD overnight followed by growth on SC+5-FOA glucose medium. Approximately $5 \%$ of $5^{\prime}$-region and $4 \%$ of $3^{\prime}$-region primary mutants were unable to lose the modular mini-Ty1-HIS3 donor plasmid. Genomic integration of the modular mini-Ty1-HIS3 donor plas- 
mid is known to prevent growth on 5-FOA. Therefore, these primary mutants were not pursued further.

A significant fraction $(37 \%)$ of the $5^{\prime}$-region primary mutants were found to have acquired the helper's multiply mutated PBS, thus we designed a colony PCR assay to identify and discard this class of mutants. Using primers JB3098 (5'-AATTCT CATGGGTCGGCG-3' ${ }^{\prime}$ ) and JB3099 (5'-GCCATAAGAGAAGC CACC- $\left.3^{\prime}\right)$, we assayed for the presence of a $0.6-\mathrm{kb}$ PCR product, which at a stringent annealing temperature $\left(54^{\circ} \mathrm{C}\right)$ could only be generated if the $3^{\prime}$-end of JB3098 annealed to the multiply mutated PBS sequence (the underlined bases in JB3098 are complementary to the mutated PBS). Fortunately, only $2 \%$ of the $3^{\prime}$ region primary mutants acquired the helper PBS. This dramatic difference between the $5^{\prime}$ - and $3^{\prime}$-regions was probably due to extensive homology upstream of the $5^{\prime}$-region shared by the modular mini-Ty1-HIS3 donor plasmid and the helper plasmid, while no such homology existed between the two plasmids near the $3^{\prime}$-region.

\section{Donor plasmid rescue and sequencing}

Yeast colonies containing modular mini-Ty1-HIS3 donor and helper plasmids were patched and passaged two to three times on SC-His-Ura plates with $2 \%$ glucose to allow the cells to lose the helper plasmid. Modular mini-Ty1-HIS3 donor plasmids were recovered into Escherichia coli by isolating total DNA from yeast patches using the glass bead-phenol method (Kaiser et al. 1994) followed by transformation of chemically competent bacteria JBe181 and selection on M9 medium lacking uracil. Mutations within the modular mini-Ty1-HIS3 donor plasmids were mapped by sequencing using the same primers that were used to generate the mutagenized PCR products (JB2456 and JB2457 or JB2460 and JB2642).

\section{RNA isolation and blot analysis}

Total RNA was isolated from 10-mL cultures of yeast (strain JB740) containing pECB9C or derivatives grown in YNB supplemented with $2 \%$ casamino acids and $1 \%$ raffinose at $22^{\circ} \mathrm{C}$ or $30^{\circ} \mathrm{C}$ for $\sim 6 \mathrm{~h}$. Glucose (represses) or galactose (induces pGal-Tyl expression and transposition) was added to $2 \%$, and cultures were grown at $22^{\circ} \mathrm{C}$ for $24-34$ h. Total RNA was extracted by hot acid phenol (Collart and Oliviero 1993) and fractionated by denaturing gel electrophoresis as described below. For quantification of ACT1 and Tyl-mhis3AI RNAs, $20 \mu \mathrm{g}$ of total RNA was heat-denatured in sample buffer (55\% deionized formamide, MOPS buffer at $\mathrm{pH} 7.0$, $5 \%$ formaldehyde, $8 \mathrm{mM}$ EDTA, and $0.1 \%$ bromophenol blue) before electrophoresis on 1\% agarose gels containing MOPS buffer (pH 7.0) (40 mM MOPS, $10 \mathrm{mM}$ sodium acetate, and $1 \mathrm{mM}$ EDTA) and 2\% formaldehyde. RNA was transferred by capillary action and fixed by UV cross-linking to Gene Screen Plus filters as described by the manufacturer (NEN Life Science Products). Membrane-bound RNAs were hybridized to ACT1-specific (1.2$\mathrm{kb}$ BamHI-HindIII fragment of $\mathrm{p} \Delta 10-\mathrm{AHX} 3$ ) (Chapman and Boeke 1991) and HIS3-specific (0.5-kb KpnI fragment of pECB4B) DNA probes that were internally labeled and purified over G25 Sephadex spin columns. Filters were exposed to a Molecular Dynamics PhosphorImager screen. Quantification of the relative steady-state transcripts (ratio of Tyl-mhis3AI/ACT1) was done using a Storm Imaging System with ImageQuant v1.11 (Molecular Dynamics) and Microsoft Excel software.

\section{VLP isolation and analysis}

Yeast (strain JB740) cells harboring pECB9C or derivatives were grown in $2 \%$ galactose at $22^{\circ} \mathrm{C}$ for $\sim 24 \mathrm{~h}$ as described previously (Eichinger and Boeke 1988). Cell pellets (4 g) from these 0.5-L cultures were resuspended in $5 \mathrm{~mL}$ of buffer B/EDTA and VLPs were isolated as described (Eichinger and Boeke 1988). During fractionation of the VLP gradients, the fractions were monitored for their absorbance at $254 \mathrm{~nm}$. RNA was isolated from VLPs as described (Fu and Rein 1993), and 5\% of the DNase-treated RNA isolated form the various VLP samples were fractionated by denaturing gel electrophoresis and analyzed as described above.

\section{cDNA analysis}

Lawns of yeast (strain JB740) transformed with pECB9C-based vectors were scraped from SC-Ura plates with $2 \%$ glucose and resuspended in $10 \mathrm{~mL}$ of YNB medium containing $2 \%$ casamino acids and $1 \%$ raffinose. Cells were grown at $30^{\circ} \mathrm{C}$ for $\sim 6 \mathrm{~h}$ to exhaust remaining glucose. Galactose was then added to $2 \%$, and cultures were incubated at $22^{\circ} \mathrm{C}$ or $30^{\circ} \mathrm{C}$ for $24-34 \mathrm{~h}$. Cells were harvested as described (Lawler et al. 2001), and genomic DNA was isolated (Boeke et al. 1985) from 11-mL cultures and then digested with AflII. DNA fragments were fractionated by agarose gel electrophoresis and transferred to Gene Screen Plus filters (NEN Life Science Products). Hybridization was measured using a Molecular Dynamics PhosphorImager. The ratio of HIS3-specific hybridization for the Tyl cDNA fragment $(2.2 \mathrm{~kb})$ relative to that of the pECB9C fragment $(14.3 \mathrm{~kb})$ provided a measure of the relative amount of Tyl cDNA.

\section{ACKNOWLEDGMENTS}

We thank the members of the Boeke laboratory for helpful discussions and reagents, especially Anne Norris. We also thank Angeli Hung for technical support during mutagenesis and screening of the $3^{\prime}$-region and Dong Shen for assistance with plasmid construction. This work was supported by NIH grant RO1 GM36481 to J.B.

Received May 17, 2004; accepted December 8, 2004.

\section{REFERENCES}

Belcourt, M.F. and Farabaugh, P.J. 1990. Ribosomal frameshifting in the yeast retrotransposon Ty: tRNAs induce slippage on a 7 nucleotide minimal site. Cell 62: 339-352.

Bieth, E., Gabus, C., and Darlix, J.L. 1990. A study of the dimer formation of Rous sarcoma virus RNA and of its effect on viral protein synthesis in vitro. Nucleic Acids Res. 18: 119-127.

Boeke, J.D. and Stoye, J.P. 1997. Retrotransposons, endogenous retroviruses, and the evolution of retroelements. In Retroviruses (eds. H. Varmus), pp. 343-435. Cold Spring Harbor Laboratory Press, Cold Spring Harbor, NY.

Boeke, J.D., LaCroute, F., and Fink, G.R. 1984. A positive selection for mutants lacking orotidine- $5^{\prime}$-phosphate decarboxylase activity in yeast: 5-fluoro-orotic acid resistance. Mol Gen Genet 197: 345-346. 
Boeke, J.D., Garfinkel, D.J., Styles, C.A., and Fink, G.R. 1985. Ty elements transpose through an RNA intermediate. Cell 40: 491500.

Boeke, J.D., Eichinger, D., Castrillon, D., and Fink, G.R. 1988a. The Saccharomyces cerevisiae genome contains functional and nonfunctional copies of transposon Ty1. Mol. Cell. Biol. 8: 1432-1442.

Boeke, J.D., Xu, H., and Fink, G.R. 1988b. A general method for the chromosomal amplification of genes in yeast. Science 239: 280-282.

Bolton, E.C., Mildvan, A.S., and Boeke, J.D. 2002. Inhibition of reverse transcription in vivo by elevated manganese ion concentration. Mol. Cell 9: 879-889.

Brachmann, R.K., Yu, K., Eby, Y., Pavletich, N.P., and Boeke, J.D. 1998. Genetic selection of intragenic suppressor mutations that reverse the effect of common p53 cancer mutations. EMBO J. 17: 1847-1859.

Braiterman, L.T. and Boeke, J.D. 1994. Ty1 in vitro integration: Effects of mutations in cis and in trans. Mol. Cell. Biol. 14: 5731-5740.

Chapman, K.B. and Boeke, J.D. 1991. Isolation and characterization of the gene encoding yeast debranching enzyme. Cell 65: 483-492.

Chapman, K.B., Byström, A.S., and Boeke, J.D. 1992. Initiator methionine tRNA is essential for Tyl transposition in yeast. Proc. Natl. Acad. Sci. 89: 3236-3240.

Clever, J.L., Wong, M.L., and Parslow, T.G. 1996. Requirements for kissing-loop-mediated dimerization of human immunodeficiency virus RNA. J. Virol. 70: 5902-5908.

Collart, M.A. and Oliviero, S. 1993. Preparation of yeast RNA. In Current protocols in molecular biology (eds. F.M. Ausubel et al.), pp. 13.12.11-13.12.15. John Wiley, New York.

Curcio, M.J. and Garfinkel, D.J. 1991. Single-step selection for Ty1 element retrotransposition. Proc. Natl. Acad. Sci. 88: 936-940.

Darlix, J.L., Gabus, C., and Allain, B. 1992. Analytical study of avian reticuloendotheliosis virus dimeric RNA generated in vivo and in vitro. J. Virol. 66: 7245-7252.

Dirac, A.M., Huthoff, H., Kjems, J., and Berkhout, B. 2001. The dimer initiation site hairpin mediates dimerization of the human immunodeficiency virus, type 2 RNA genome. J. Biol. Chem. 276: 3234532352.

Eichinger, D.J. and Boeke, J.D. 1988. The DNA intermediate in yeast Tyl element transposition copurifies with virus-like particles: Cellfree Tyl transposition. Cell 54: 955-966.

Feng, Y.X., Moore, S.P., Garfinkel, D.J., and Rein, A. 2000. The genomic RNA in Tyl virus-like particles is dimeric. J. Virol. 74: 10819-10821.

Fosse, P., Motte, N., Roumier, A., Gabus, C., Muriaux, D., Darlix, J.L., and Paoletti, J. 1996. A short autocomplementary sequence plays an essential role in avian sarcoma-leukosis virus RNA dimerization. Biochemistry 35: 16601-16609.

Friant, S., Heyman, T., Wilhelm, M.L., and Wilhelm, F.X. 1996. Extended interactions between the primer $\mathrm{tRNA}_{\mathrm{i}}{ }^{\mathrm{Met}}$ and genomic RNA of the yeast Ty1 retrotransposon. Nucleic Acids Res. 24: 441449.

Friant, S., Heyman, T., Bystrom, A.S., Wilhelm, M., and Wilhelm, F.X. 1998. Interactions between Tyl retrotransposon RNA and the T and $D$ regions of the $\mathrm{tRNA}_{\mathrm{i}}^{\mathrm{Met}}$ primer are required for initiation of reverse transcription in vivo. Mol. Cell. Biol. 18: 799-806.

$\mathrm{Fu}$, W. and Rein, A. 1993. Maturation of dimeric viral RNA of Moloney murine leukemia virus. J. Virol. 67: 5443-5449.

Garfinkel, D.J., Boeke, J.D., and Fink, G.R. 1985. Ty element transposition: Reverse transcriptase and virus-like particles. Cell 42: $507-517$.

Heyman, T., Agoutin, B., Friant, S., Wilhelm, F.X., and Wilhelm, M.L. 1995. Plus-strand DNA synthesis of the yeast retrotransposon Ty1 is initiated at two sites, PPT1 next to the $3^{\prime}$ LTR and PPT2 within the pol gene. J. Mol. Biol. 253: 291-303.

Hill, M.K., Shehu-Xhilaga, M., Campbell, S.M., Poumbourios, P., Crowe, S.M., and Mak, J. 2003. The dimer initiation sequence stem-loop of human immunodeficiency virus type 1 is dispensable for viral replication in peripheral blood mononuclear cells. J. Virol. 77: 8329-8335.
Kaiser, C.S., Michaelis, S., and Mitchell, A. 1994. Methods in yeast genetics, A Cold Spring Harbor Laboratory course manual. Cold Spring Harbor Laboratory Press, Cold Spring Harbor, NY.

Kim, C.H. and Tinoco Jr., I. 2000. A retroviral RNA kissing complex containing only two G. C base pairs. Proc. Natl. Acad. Sci. 97: 9396-9401.

Lanchy, J.M. and Lodmell, J.S. 2002. Alternate usage of two dimerization initiation sites in HIV-2 viral RNA in vitro. J. Mol. Biol. 319: 637-648.

Laughrea, M. and Jette, L. 1994. A 19-nucleotide sequence upstream of the $5^{\prime}$ major splice donor is part of the dimerization domain of human immunodeficiency virus 1 genomic RNA. Biochemistry 33: $13464-13474$

- 1996. Kissing-loop model of HIV-1 genome dimerization: HIV-1 RNAs can assume alternative dimeric forms, and all sequences upstream or downstream of hairpin 248-271 are dispensable for dimer formation. Biochemistry 35: 1589-1598.

Lawler, J.F., Merkulov, G.V., and Boeke, J.D. 2001. Frameshift signal transplantation and the unambiguous analysis of mutations in the yeast retrotransposon Ty1 Gag/Pol overlap region. J. Virol. 75: 6769-6775.

Levin, H.L. 1995. A novel mechanism of self-primed reverse transcription defines a new family of retroelements. Mol. Cell. Biol. 15:3310-3317.

Lin, J.H. and Levin, H.L. 1997. A complex structure in the mRNA of Tf1 is recognized and cleaved to generate the primer of reverse transcription. Genes \& Dev. 11: 270-285.

Ly, H. and Parslow, T.G. 2002. Bipartite signal for genomic RNA dimerization in Moloney murine leukemia virus. J. Virol. 76: 31353144.

Mathews, D.H., Sabina, J., Zuker, M., and Turner, D.H. 1999. Expanded sequence dependence of thermodynamic parameters improves prediction of RNA secondary structure. J. Mol. Biol. 288: 911-940.

Monokian, G.M., Braiterman, L.T., and Boeke, J.D. 1994. In-frame linker insertion mutagenesis of yeast transposon Tyl: Mutations, transposition and dominance. Gene 139: 9-18.

Moore, S.P., Powers, M., and Garfinkel, D.J. 1995. Substrate specificity of Ty1 integrase. J. Virol. 69: 4683-4692.

Muhlrad, D., Hunter, R., and Parker, R. 1992. A rapid method for localized mutagenesis of yeast genes. Yeast 8: 79-82.

Mumberg, D., Muller, R., and Funk, M. 1995. Yeast vectors for the controlled expression of heterologous proteins in different genetic backgrounds. Gene 156: 119-122.

Oroudjev, E.M., Kang, P.C., and Kohlstaedt, L.A. 1999. An additional dimer linkage structure in Moloney murine leukemia virus RNA. J. Mol. Biol. 291: 603-613.

Paillart, J.C., Berthoux, L., Ottmann, M., Darlix, J.L., Marquet, R., Ehresmann, B., and Ehresmann, C. 1996a. A dual role of the putative RNA dimerization initiation site of human immunodeficiency virus type 1 in genomic RNA packaging and proviral DNA synthesis. J. Virol. 70: 8348-8354.

Paillart, J.C., Marquet, R., Skripkin, E., Ehresmann, C., and Ehresmann, B. 1996b. Dimerization of retroviral genomic RNAs: Structural and functional implications. Biochimie 78: 639-653.

Paillart, J.C., Shehu-Xhilaga, M., Marquet, R., and Mak, J. 2004. Dimerization of retroviral RNA genomes: An inseparable pair. Nat. Rev. Microbiol. 2: 461-472.

Rabson, A.B. and Graves, B.J. 1997. Synthesis and processing of viral RNA. In Retroviruses (eds. H. Varmus et al.), pp. 205-261. Cold Spring Harbor Laboratory Press, Cold Spring Harbor, NY.

Roth, J.F. 2000. The yeast Ty virus-like particles. Yeast 16: 785-795.

Russell, R.S., Hu, J., Beriault, V., Mouland, A.J., Laughrea, M., Kleiman, L., Wainberg, M.A., and Liang, C. 2003. Sequences downstream of the $5^{\prime}$ splice donor site are required for both packaging and dimerization of human immunodeficiency virus type 1 RNA. J. Virol. 77: 84-96.

Sakuragi, J., Ueda, S., Iwamoto, A., and Shioda, T. 2003. Possible role of dimerization in human immunodeficiency virus type 1 genome RNA packaging. J. Virol. 77: 4060-4069. 


\section{Bolton et al.}

Sharon, G., Burkett, T.J., and Garfinkel, D.J. 1994. Efficient homologous recombination of Ty1 element cDNA when integration is blocked. Mol. Cell. Biol. 14: 6540-6551.

Shen, N., Jette, L., Liang, C., Wainberg, M.A., and Laughrea, M. 2000. Impact of human immunodeficiency virus type 1 RNA dimerization on viral infectivity and of stem-loop B on RNA dimerization and reverse transcription and dissociation of dimerization from packaging. J. Virol. 74: 5729-5735.

Sherman, F., Fink, G.R., and Hicks, J.B. 1986. Methods in yeast genetics. Cold Spring Harbor Laboratory, Cold Spring Harbor, NY.

Skripkin, E., Paillart, J.C., Marquet, R., Ehresmann, B., and Ehresmann, C. 1994. Identification of the primary site of the human immunodeficiency virus type 1 RNA dimerization in vitro. Proc. Natl. Acad. Sci. 91: 4945-4949.

Swanstrom, R. and Wills, J.R. 1997. Synthesis, assembly, and processing of viral proteins. In Retroviruses (eds. H. Varmus et al.), pp. 263-334. Cold Spring Harbor Laboratory Press, Cold Spring Harbor, NY.

Telesnitsky, A. and Goff, S.P. 1993. Strong-stop strand transfer during reverse transcription. In Reverse transcriptase (eds. A.M. Skalka and S.P. Goff), pp. 49-83. Cold Spring Harbor Laboratory Press, Cold Spring Harbor, NY.
Tounekti, N., Mougel, M., Roy, C., Marquet, R., Darlix, J.L., Paoletti, J., Ehresmann, B., and Ehresmann, C. 1992. Effect of dimerization on the conformation of the encapsidation Psi domain of Moloney murine leukemia virus RNA. J. Mol. Biol. 223: 205-220.

Uzun, O. and Gabriel, A. 2001. A Tyl reverse transcriptase active-site aspartate mutation blocks transposition but not polymerization. $J$. Virol. 75: 6337-6347.

Voytas, D.F. and Boeke, J.D. 2002. Ty1 and Ty5 of Saccharomyces cerevisiae. In Mobile DNA II (eds. N.L. Craig et al.), pp. 631-662. American Society of Microbiology Press, Washington, DC.

Wilhelm, M., Heyman, T., Boutabout, M., and Wilhelm, F.X. 1999. A sequence immediately upstream of the plus-strand primer is essential for plus-strand DNA synthesis of the Saccharomyces cerevisiae Ty1 retrotransposon. Nucleic Acids Res. 27: 4547-4552.

$\mathrm{Xu}, \mathrm{H}$. and Boeke, J.D. 1987. High-frequency deletion between homologous sequences during retrotransposition of Ty elements in Saccharomyces cerevisiae. Proc. Natl. Acad. Sci. 84: 8553-8557.

. 1990. Localization of sequences required in cis for yeast Ty1 element transposition near the long terminal repeats: analysis of mini-Ty1 elements. Mol. Cell. Biol. 10: 2695-2702.

Zuker, M. 2003. Mfold web server for nucleic acid folding and hybridization prediction. Nucleic Acids Res. 31: 3406-3415 

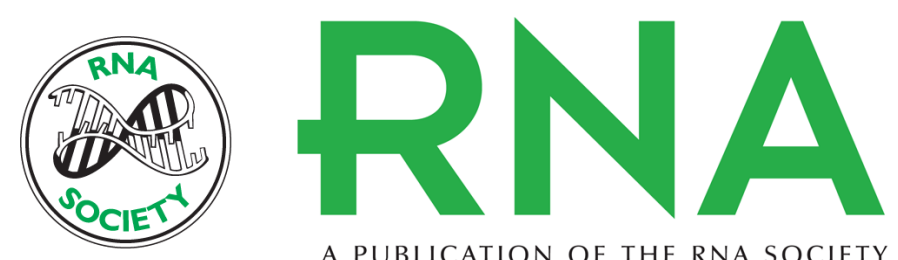

A PUBLICATION OF THE RNA SOCIETY

\section{Identification and characterization of critical cis-acting sequences within the yeast Ty1 retrotransposon}

ERIC C. BOLTON, CANDICE COOMBES, YOLANDA EBY, et al.

RNA 2005 11: 308-322

References This article cites 52 articles, 27 of which can be accessed free at:

http://rnajournal.cshlp.org/content/11/3/308.full.html\#ref-list-1

\section{License}

Email Alerting Receive free email alerts when new articles cite this article - sign up in the box at the Service top right corner of the article or click here. 